\title{
CRANE CABINS' SAFETY AND ERGONOMICS CHARACTERISTICS EVALUATION BASED ON DATA COLLECTED IN SWEDEN PORT
}

\author{
Zorica Veljković* \\ Faculty of Mechanical Engineering, Belgrade, Serbia \\ Vesna Spasojević-Brkić \\ Faculty of Mechanical Engineering, Belgrade, Serbia \\ Aleksandar Brkić \\ Innovation Center, Faculty of Mechanical Engineering, Belgrade, Serbia
}

This paper presents an evaluation of crane cabins safety and ergonomics characteristics. It is based on previous research data collected for benchmarking analysis for crane cabins operating in one port in Sweden. Six crane cabin types are examined regarding eight characteristic divided in three groups: operator-control devices interaction, safety and anthropometric adjustment according to needs weighting data. Primary analysis of those data was conducted using Pareto analysis. Further analysis are done using developed indexes of characteristics performances while final conclusions were drawn for characteristic of crane cabins using crane index of performance. Taking into account all examined crane cabins only $52.5 \%$ of operator- control devices interaction, $75 \%$ of safety and $60 \%$ of anthropometric adjustment issues are satisfied in current designs.

Key words: Crane cabin, Operator-control devices interaction, Safety, Anthropometric adjustment, Pareto analysis, Index of performance, Crane index of performance

\section{INTRODUCTION}

The study of interaction between man and machine in the system, with regard to the improvements/adjustments in order to improve the efficiency of operations, reduce operator fatigue and protecting the health of operator and ensuring optimum working environment conditions, presents a challenge to engineers as well as many other experts that deal with this issue. Specific biological properties of man in relation to the technical requirements of the machine, which by their nature differ substantially, make this research very difficult. As the biological characteristics in general also have certain changes, research interactions in the man-machine system, aimed at its optimization, are focused primarily on the adjustment of certain characteristics of the machine to man, to use man optimal psycho-physical abilities. Specifically, large number of research is aimed in the direction of the smallest possible expenditure of energy and time by a man while performing work operations on the machine, as well as the preservation of human health when in contact with the machine and work environment. Such investigations require knowledge, in addition to technical, from range of other scientific disciplines, which essentially requires a multidisciplinary approach to problems solving. In this regard, in order to find optimal solutions specific problem is complex linking the necessary aspects of the research on a complex basis towards the achievements of individual scientific disciplines. Till today there is not large extent of research in the field of crane cabins convenience to the operator in aim to use minimal energy and time together with preservation of human health. One of rare research is the ergonomics field is conducted in steel plant in India on overhead crane showing large number of musculoskeletal disorders due to awkward work postures and insufficient vision angle [04]. Another study, which is in great extent connected to the subject of this investigation was conducted in Sweden [01] and they survey crane cabin's operator needs with an aim to design ergonomically adapted (in sense of sturdiness, comfort and safety) and user-friendly driver environment. Authors in [01], although without deep statistical analysis, propose rotating chair with integrated 
control devices on the armrests. The third research is based on anthropometric characteristic analysis to improve safety and prevent crane related fatalities and injuries [07]. Other authors mainly identify basic or individual characteristics of crane cabins without adequate analysis [02, 03] such as sitting, visibility and noise issues, the existence of fire extinguishers, labeling the symbols, accessibility to cabin etc. [04, 05, 06]. In recent years slight shift is made toward serious research in order to design crane cabins with better ergonomic and safety characteristic which are economically viable $[07,08,09]$. Accordingly, Dondur et al in [08] conclude that new generation crane cabins with lower weight and interior space better adapted to operator could

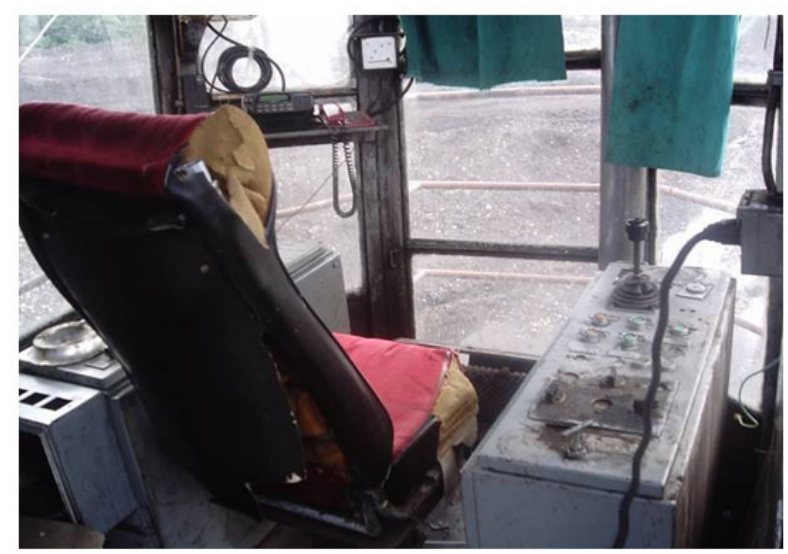

be developed by using the methods of physical, cognitive and organizational ergonomics with the main issue to solve problem of visibility and in that way allow higher productivity due to reduction of physical and psychological stress of the operator, as well as greater safety and security due to the integrated visual system. Authors in [08] even conclude that it could be a project with low economic risk. However, the importance of studying of this problem greatly exceeds the number of published papers. Back and lower limb disorders occur very often to crane operators [10] and almost $30 \%$ of them feels extremely uncomfortable $[07,11]$. One of crane cabins that operates in Serbia is shown in Figure 1.

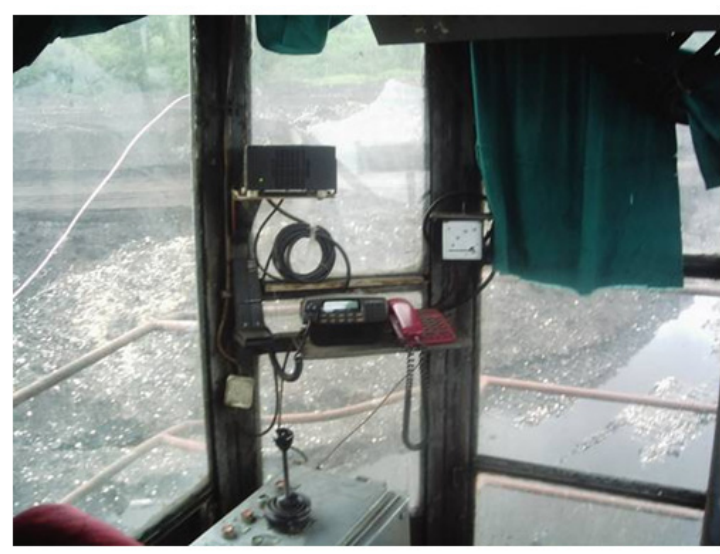

Figure 1: Interior of crane cabin that operates in Serbia

In construction and maintenance sectors cranes contribute to one-third of all fatalities, while large numbers of injuries and deaths is also encountered in transportation, manufacturing and warehousing industry sectors $[07,12]$. According to evident need this paper describes continuation of research on evaluation of crane cabin char- acteristics that operate in one Sweden port. It is based on benchmarking research data of Nordin and Olson [01] which is conducted in 2008. Results of their research are analyzed by Pareto method in order to obtain more precise data important for future crane cabins' design.

Table 1. Modified benchmarking table with grading criteria [01]

\begin{tabular}{|c|c|c|c|c|c|c|c|c|c|}
\hline & $\begin{array}{l}\frac{\mathrm{d}}{0} \\
\frac{0}{0}\end{array}$ & characteristics & 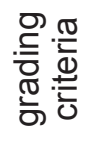 & $\frac{\mathbb{D}}{\frac{\Phi}{3}}$ & 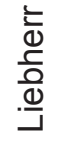 & 을일 & $\overline{\bar{Y}}$ & : & 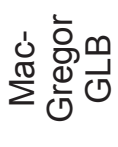 \\
\hline 1 & USI & Understandable signals & 5 & 4 & 4 & 2 & 1 & 1 & 4 \\
\hline 2 & USY & Understandable symbols & 4 & 1 & 4 & 1 & 1 & 2 & 4 \\
\hline 3 & SCD & See the content of the display & 4 & 4 & 3 & 1 & 1 & 1 & 2 \\
\hline 4 & SCC & See the cargo, wharf and closest surrounding & 5 & 4 & 3 & 4 & 1 & 3 & 3 \\
\hline 5 & FIC & Fixed items in cabin & 4 & 3 & 4 & 4 & 4 & 3 & 4 \\
\hline 6 & RSP & Robust and steady parts & 4 & 4 & 4 & 3 & 3 & 3 & 4 \\
\hline 7 & LEI & $\begin{array}{l}\text { Logical and ergonomically correct placement of } \\
\text { indicators and regulators }\end{array}$ & 5 & 4 & 2 & 2 & 1 & 1 & 2 \\
\hline 8 & AWP & Adjustable work posture & 5 & 5 & 2 & 4 & 1 & 2 & 2 \\
\hline
\end{tabular}


Basic table from Nordin and Olson [01] for benchmarking (Table 1) was the starting point of this research. Semi-structured interviews with experienced crane operators and design according to [1] have shown that the following needs have to be satisfied to fulfill ergonomics and safety features: (1) the operator must see the cargo, wharf and closest surrounding (2) the operator must understand signals and symbols in cabin (3) the operator has the need to see the display (4) all parts in cabin must be robust and steady due to often careless behavior of operators (5) the placement of indicators and regulators must be logical and ergonomically correct (6) the operator has the need for adjustable work posture and (7) there is a need to have all items fixed in cabin due to risk of theft. As shown in Table 1, this research is based on examination of eight criteria on six different crane cabins' design solutions. It is presumed that Lulea port cranes have the same cabins for all cranes regardless crane manufacturer or crane characteristics [01]. Grading criteria are based on Likert scales 1 to 4 and 1 to 5 depending of examined characteristic, where 1 represents that examined characteristics doesn't fulfill the operators' needs for required characteristics, while 4 or 5 represent that it fulfills all desired characteristic criteria. Further distribution of characteristics (Table 1 ) is conducted by dividing them in three major groups [01]:

- operator - control devices interaction (Table 1, characteristics 1-3),

- safety (Table 1, characteristics 4 and 5 ) and anthropometric adjustment (Table 1, characteristics 6-8).

\section{METHODOLOGY}

\section{Measurement of index of performance of characteristics}

Purpose of this analysis includes comparison between characteristics, impacts of individual characteristics on types of crane cabins, as well as overall appraisal of characteristics of different crane cabin types and appraisal from group types point of view. In order to compare different types of crane cabins (Table 1), scores obtained by Likert scale were transformed and equalized by introduction of index of performance IP and crane index of performance CIP.

Index of performance of characteristics can be defined as:

$I P_{i j}=g_{i j} / \max \left(c_{j}\right)$

where $I P_{i j}$ is the index of the single characteristic $(i=1 \ldots 6)$ for individual cranes $(j=1 \ldots 8)$ from Table $1, g_{i j}$ is grade for crane characteristics, while cj, is maximum value of Likert scale for observed characteristic. Crane index of performance CIP is the sum of individual values of IP (1) for certain crane, i.e.

$$
C I P_{i}=\sum_{i=1}^{8} I P_{j}, \mathrm{i}=1, \ldots, 6
$$

where ${ }^{i}=1 \mathrm{P} i$ is one of the cranes $i=1, . ., 6$. Those results are presented in Table 2.

Table 2: Values of IP and CIP for observed cranes

\begin{tabular}{|c|c|c|c|c|c|c|c|c|}
\hline & $\begin{array}{l}\frac{\mathrm{d}}{2} \\
\frac{0}{0} \\
\frac{0}{\sigma}\end{array}$ & characteristics & $\begin{array}{l}t \\
\overline{0} \\
\mathbb{0} \\
\frac{\mathbb{d}}{3} \\
\end{array}$ & 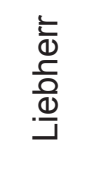 & 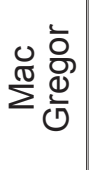 & $\frac{0}{\frac{0}{2}}$ & : & $\overline{\bar{I}}$ \\
\hline 1 & USI & Understandable signals & 0.8 & 0.8 & 0.8 & 0.4 & 0.2 & 0.2 \\
\hline 2 & USY & Understandable symbols & 0.25 & 1 & 1 & 0.25 & 0.5 & 0.25 \\
\hline 3 & SCD & See the content of the display & 1 & 0.75 & 0.5 & 0.25 & 0.25 & 0.25 \\
\hline 4 & SCC & See the cargo, wharf and closest surrounding & 0.8 & 0.6 & 0.6 & 0.8 & 0.6 & 0.2 \\
\hline 5 & FIC & Fixed items in cabin & 0.75 & 1 & 1 & 1 & 0.75 & 1 \\
\hline 6 & RSP & Robust and steady parts & 1 & 1 & 1 & 0.75 & 0.75 & 0.75 \\
\hline 7 & LEI & $\begin{array}{l}\text { Logical and ergonomically correct placement of } \\
\text { indicators and regulators }\end{array}$ & 0.8 & 0.4 & 0.4 & 0.4 & 0.2 & 0.2 \\
\hline \multirow[t]{2}{*}{8} & AWP & Adjustable work posture & 1 & 0.4 & 0.4 & 0.8 & 0.4 & 0.2 \\
\hline & & CIP & 6.4 & 5.95 & 5.7 & 4.65 & 3.65 & 3.05 \\
\hline
\end{tabular}


Based on examined criteria it can be concluded that crane cabins with best performances according to needs weighting are found at Lulea port (6.4), followed by cabins produced by Liebherr and MacGregor (5.95 and 5.95), while smallest CIP has MHI crane cabin (3.05). It can be also noticed that sums for all cabins show that only fixed items in cabin and robust and steady parts have marks above 5 of 6 , that means that all other characteristics could be improved. Values of IP and CIP based on group characteristics: operator- control devices interaction, safety and anthropometric adjustment, are presented in Table 3.

Table 3: Values of IP for group characteristics - interaction, safety and ergonomics

\begin{tabular}{|c|c|c|c|c|c|c|c|}
\hline & characteristics by group & $\begin{array}{l}\frac{1}{0} \\
\frac{0}{\mathbb{J}} \\
\frac{\mathbb{J}}{J}\end{array}$ & 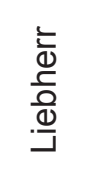 & 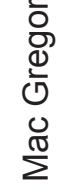 & $\frac{O}{\frac{2}{2}}$ & : & $\overline{\bar{I}}$ \\
\hline $\mathrm{ICO}$ & operator- control devices interaction & 2.05 & 2.55 & 2.3 & 0.9 & 0.95 & 0.7 \\
\hline SA & safety & 1.55 & 1.6 & 1.6 & 1.8 & 1.35 & 1.2 \\
\hline \multirow[t]{2}{*}{ ER } & anthropometric adjustment & 2.8 & 1.8 & 1.8 & 1.95 & 1.35 & 1.15 \\
\hline & CIP & 6.4 & 5.95 & 5.7 & 4.65 & 3.65 & 3.05 \\
\hline
\end{tabular}

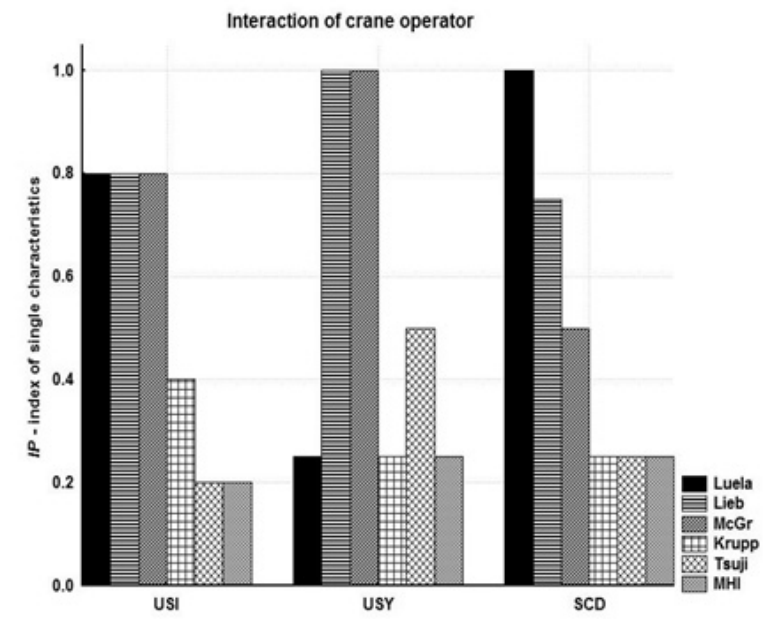

(a)

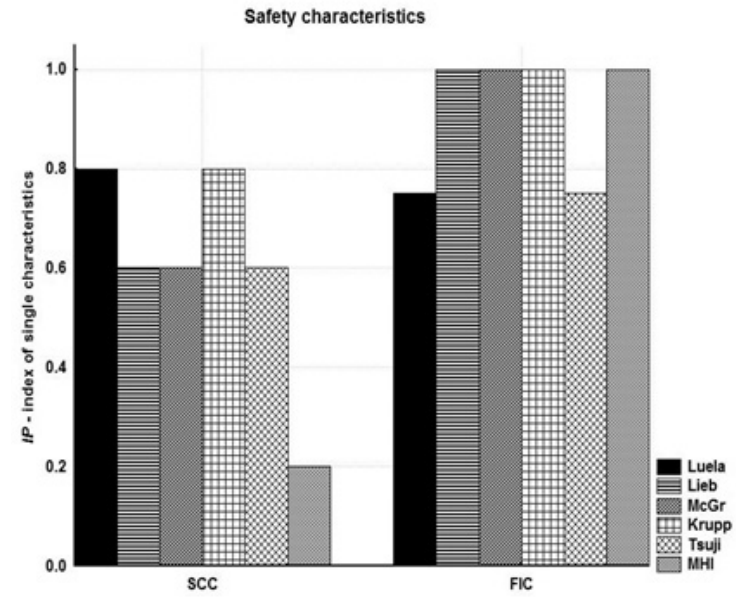

(b)

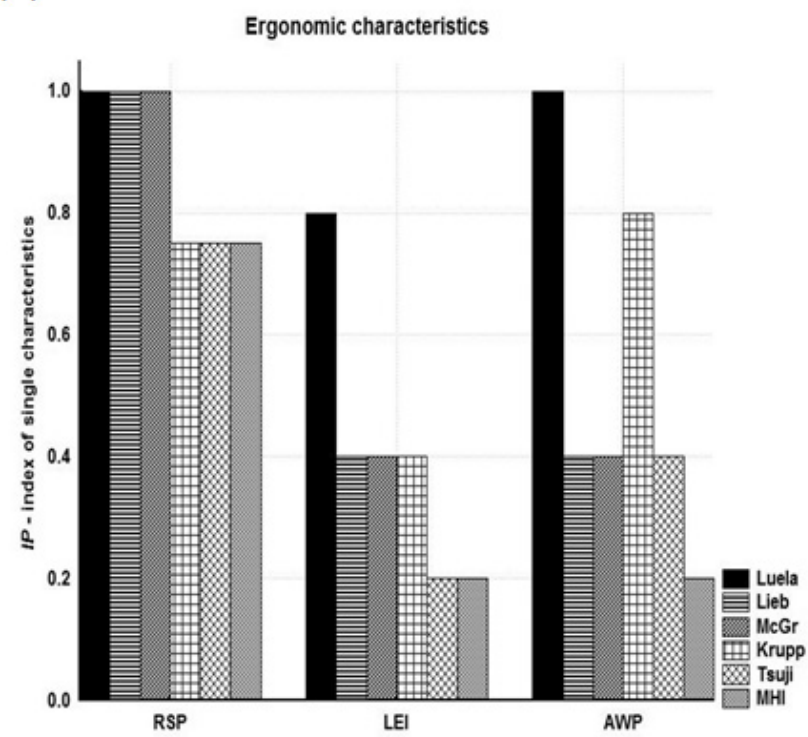

(c)

Figure 2: Measured characteristic for interaction between crane operator and control devices (a), safety (b) and anthropometric adjustment (c) 
From Table 3 it could be concluded that best interaction between control devices and crane operator has Liebherr crane cabin (2.55), following by MacGregor and Lulea port cabins (2.3 and 2.05). They are in the upper third of measurement scale while for the rest of examined crane cabins IP is significantly smaller. Regarding safety characteristics (Table 3) Krupp crane cabin has the best safety characteristics (1.8), followed by Liebherr and MacGregor cabins (1.6). As for anthropometric adjustment characteristics, the best results are obtained by crane cabins from Lulea port (2.8), followed by Krupp (1.95) and Liebherr and MacGregor (1.8). Only Lulea port cabins' anthropometric adjustment characteristics are on the upper third of measurement scale also with maximum estimate of CIP for surveyed characteristics. Results from Table 3 are presented on Figure 2.

\section{Pareto analysis}

Influence of observed crane cabin characteristics is further conducted using Pareto analysis. In this case all characteristics are observed equally, regardless on type, starting from the characteristic that is least good. Pareto analysis for crane cabins in Luela port is presented at Figure 3.

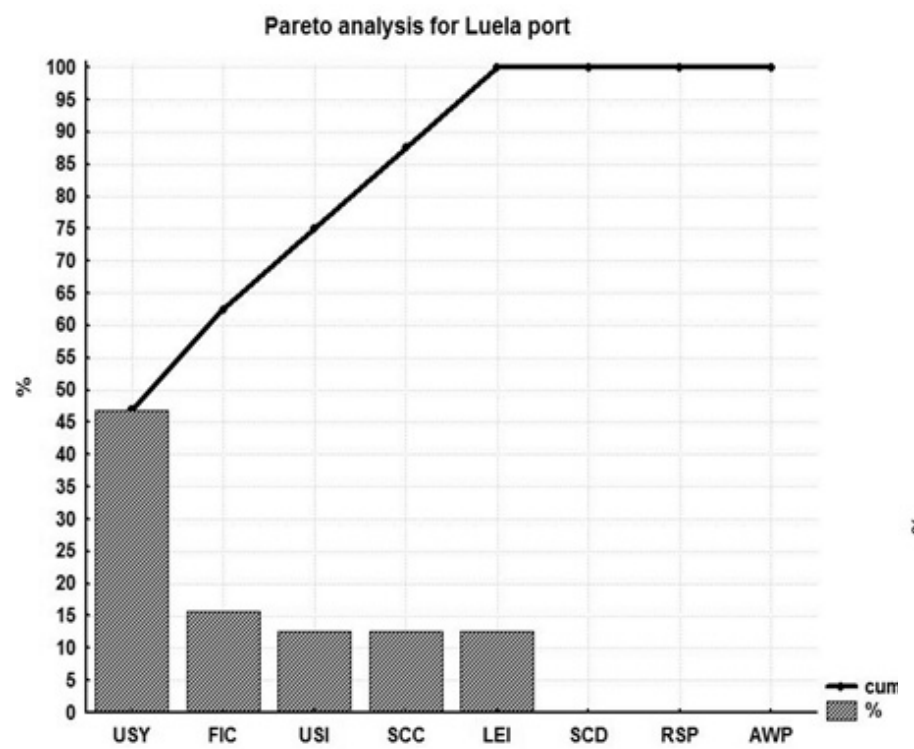

Figure 3: Pareto analysis for characteristics of crane cabins for Lulea port

Analysis of data for Lulea port crane cabins indicates that critical characteristic is symbols understanding with participation of $46.88 \%$. Fixed item in cabin amount $15.63 \%$ followed by understandable signals or seeing the cargo, wharf and closest surrounding or placement of indicators with $12.5 \%$. Mentioned characteristics represent $75 \%$ of problems in Lulea port crane cabins. Liebherr crane cabin characteristics are expressed by Pareto graph as shown at Figure 4.

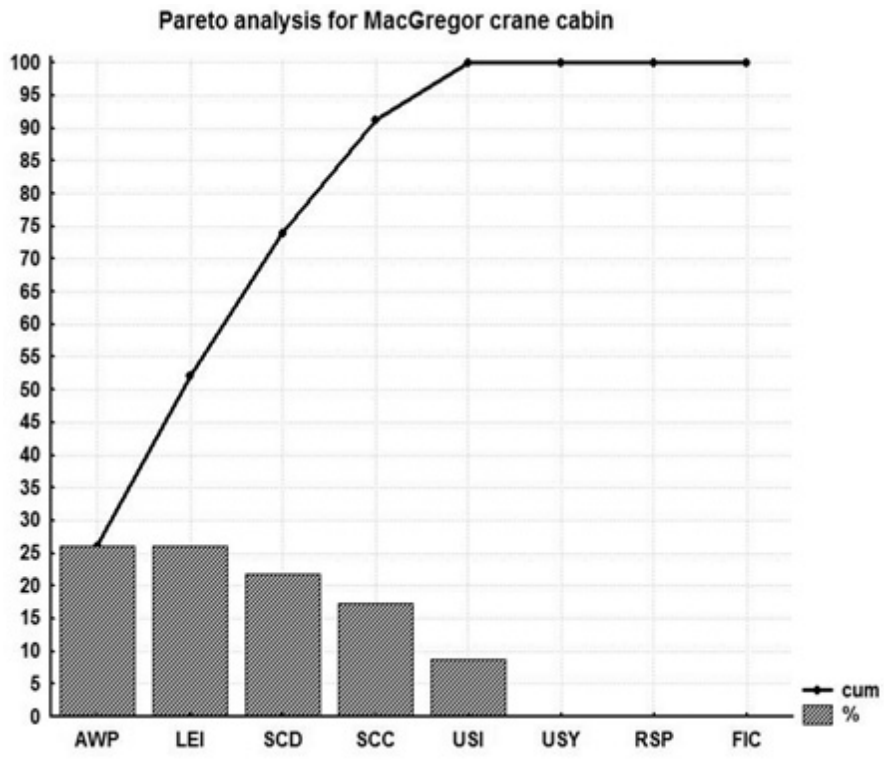

Figure 4: Pareto analysis for characteristics of Liebherr crane cabin

Majority of influence on Liebherr's crane cabin characteristics (80\%) have placement of indicators and regulators and adjustable work posture with $29.67 \%$ each and seeing cargo, wharf and closest surroundings with $19.51 \%$ of influence. For MacGregor's crane cabin characteristics Pareto graph is shown at Figure 5.

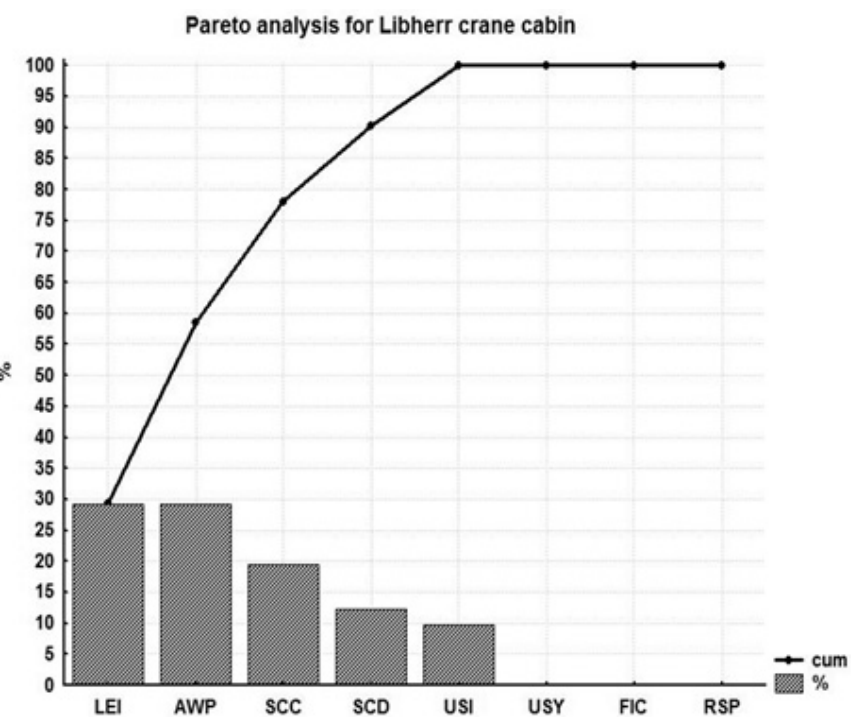

Figure 5: Pareto analysis for characteristics for MacGregor type of crane cabin

Influential characteristics of MacGregor crane cabin are adjustable work posture and placement of indicators and regulators with influence of $26.09 \%$ each, while visibility of content of 
display has an influence that amounts $21.74 \%$. Those characteristics cover $73.92 \%$ problems in MacGregor type of crane cabin. If see cargo, wharf and closest surrounding is included with $17.39 \%$ of influence, than $91.31 \%$ of problems are covered. Rest of observed types of crane cabins, i.e. Krupp, Tsuji and $\mathrm{MHI}$ are described together since their crane index of performance is significantly lower than above described types (Table 2). For Krupp crane cabin characteristics Pareto graph is shown at Figure 6, for Tsuji at Figure 7 and for $\mathrm{MHI}$ at Figure 8.

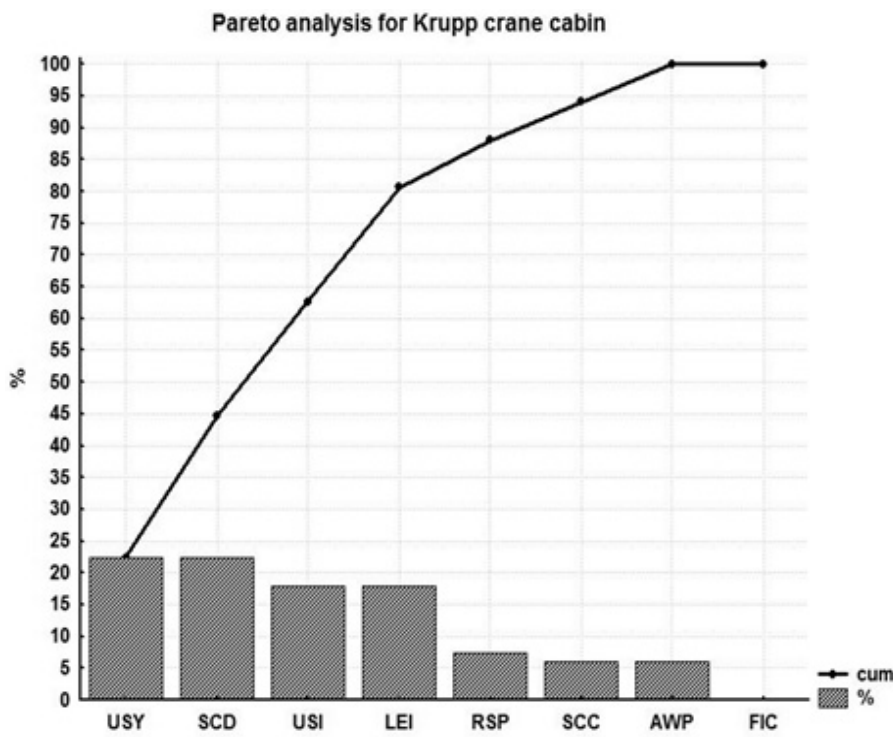

Figure 6: Pareto analysis for characteristics for Krupp type of crane cabin

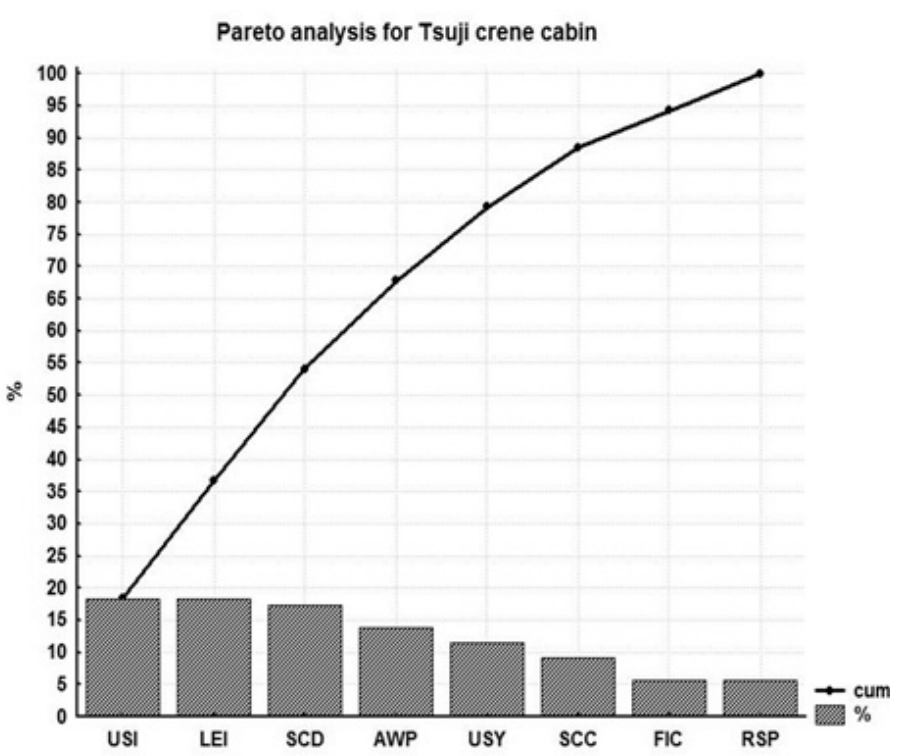

Figure 7: Pareto analysis for characteristics for Tsuji type of crane cabin

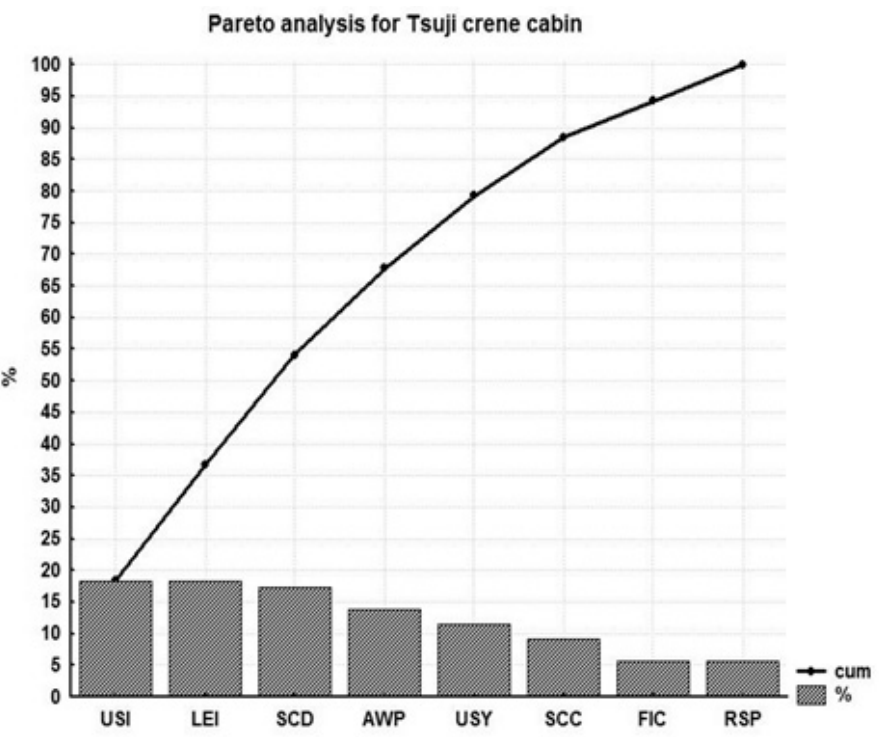

Figure 8. Pareto analysis for characteristics for $\mathrm{MHI}$ type of crane cabin

Krupp crane cabins have four influential characteristic, while Tsuji and $\mathrm{MHI}$ have 5 influential characteristics with $75 \%$ of influence.

\section{Index of unsuitability}

Beside Pareto analysis of characteristics, overall comparison was conducted using index of unsuitability of crane types. Let index of unsuitability IU be

$$
I U C_{i j}=1-I P_{i j}, i=1, \ldots, 8, j=1, \ldots, 6
$$

with overall index of unsuitability of crane cabin characteristic based on (3)

$$
U C I P_{j}=\sum_{i}^{8} I U C_{i j}, j=1, \ldots, 8, j=1, \ldots, 6
$$

$U C I P_{i}$, values obtained from (4) for all crane cabins are shown at Figure 9.

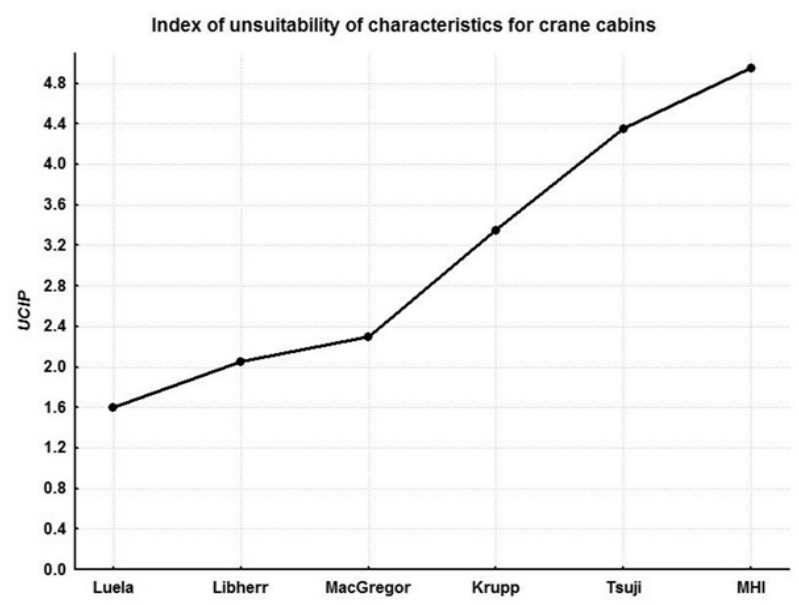

Figure 9: Indexes of unsuitability for considered crane types 


\section{CONCLUSION}

Conducted analysis of the considered crane cabins and their characteristics according to operators' needs satisfaction given in [1] and according to analysis done in this paper leads to following conclusions:

- Taking into account all crane cabins only $52.5 \%$ of operator- control devices interaction, $75 \%$ of safety and $60 \%$ of anthropometric adjustment issues are satisfied in current designs.

- It is evident from Figure 8 that even the best rated Lulea cabins still have a room for $20 \%$ improvement, while $\mathrm{MHI}$ cabins have unsuitability that amounts $62.5 \%$.

- Best characteristics have crane cabins at Lulea port and they are followed by Liebherr and MacGregor producers.

- Crane cabins at Lulea port and from Liebherr and MacGregor producers have significantly better characteristics than Krupp, Tsuji and $\mathrm{MHI}$ crane cabins regarding considered safety and ergonomics characteristics.

- Main problems for Lulea port crane cabins are in the fields of interaction between crane operator and controls followed by safety characteristics.

- Liebherr and MacGregor crane cabins could be improved by better placement of indicators and regulators and adjustable work posture, followed by the solution of visual problems of operator.

It is evident that contemporary crane cabins designs still do not satisfy operator needs in the fields of both safety and ergonomics and according to that future research are expected in those aims. Authors in [13] also propose further research since performance and physical load on the operator should be further optimized by adjusting gain settings to the task, especially in the field of joystick design.

\section{ACKNOWLEDGEMENTS}

This paper is result of projects CABIVS (E!6761) and SPRINCE, supported by Eureka network and the consortium ERA-NET SAFERA - Coordination of European Research on Industrial Safety towards Smart and Sustainable Growth under the Seventh Framework Programme for Research and Technological Development. The University of Messina and the FME University of Belgrade, respectively, acknowledge INAIL (Istituto Nazionale per l'Assicurazione contro gli Infortuni sul Lavoro) and MESTD (Ministry of Education, Science and Technological Development) for the funding.

\section{REFERENCES}

1) Nordin, F., Olsson, S. (2008). Development of driver environment crane cabin, Master Thesis, Lulea University of technology, ISSN: 1402-1617-ISRN: LTU -EC--08/227--SE

2) Health and safety Queensland, (2006). Tower crane Compliance campaign 2005 report, Queensland Government, Department of Industrial relations

3) Darley, P.M., Liang, J. (1998). Crane Modernization - Why and How?. TOCASIA 1998

4) Ray, P. K., \& Tewari, V. K. (2011). Ergonomic design of crane cabins: a case study from a steel plant in India. Work (Reading, Mass.), 41, pp.5972-5976.

5) Cheng, T., Teizer, J. (2011, June). Crane operator visibility of ground operations. In Proceedings of the 28th International Symposium on Automation and Robotics in Construction, Seoul, Korea.

6) Lee, G., Cho, J., Ham, S., Lee, T., Lee, G., Yun, S. H., Yang, H. J. (2012). A BIM-and sensor-based tower crane navigation system for blind lifts. Automation in construction, 26, pp. 1-10.

7) Brkić, V. S., Klarin, M. M., Brkić, A. D. (2015). Ergonomic design of crane cabin interior: The path to improved safety. Safety science, 73, pp.43-51.

8) Dondur, N., Spasojević-Brkić, V., \& Brkić, A. (2012). Crane cabins with integrated visual systems for the detection and interpretation of environment-economic appraisal. Journal of Applied Engineering Science, 10(4), 191196.

9) Mardiyanto, E., Ardyanto, D., \& Notobroto, H. B. (2015). Container Crane Operator Ergonomics Analysis PT. X Port of Tanjung Perak, Surabaya. Civil and Environmental Research, Vol. 7, No. 4, pp. 86-89.

10) Punnett, L., Wegman, D. H. (2004). Work-related musculoskeletal disorders: the epidemiologic evidence and the debate. Journal of Electromyography and Kinesiology, Vol. 14. No. 1, pp.13-23. 
11) Tam, V. W., Fung, I. W. (2011). Tower crane safety in the construction industry: A Hong Kong study. Safety Science, Vol. 49, No. 2, pp. 208-215.

12) Neitzel, R. L., Noah S. S., Ren K. (2001). A review of crane safety in the construction industry. Applied Occupational and Environmental Hygiene, Vol. 16, No. 12, pp 11061117.

13) Huysmans, M. A., De Looze, M. P., Hoozemans, M. J., Van Der Beek, A. J., \& Van
Dieen, J. H. (2006). The effect of joystick handle size and gain at two levels of required precision on performance and physical load on crane operators. Ergonomics, Vol.49, No.11, pp.1021-1035.

Paper sent to revision: 20.10.2015.

Paper ready for publication: 15.12.2015. 